\title{
Lipid peroxidation levels in rat cardiac muscle are affected by age and thyroid status
}

\author{
R Shinohara', T Mano², A Nagasaka², R Hayashi ${ }^{2}$, K Uchimura $^{2}$, \\ I Nakano², F Watanabe'2, T Tsugawa², M Makino², H Kakizawa², \\ M Nagata ${ }^{2}, K_{\text {Iwase }}{ }^{3}, Y$ Ishizuki $^{4}$ and $M$ Itoh $^{2}$ \\ ${ }^{1}$ Department of Biochemistry, Fujita Health University School of Hygiene, Toyoake, Aichi 470-1192, Japan \\ ${ }^{2}$ Department of Internal Medicine and Surgery, Fujita Health University School of Medicine, Toyoake, Aichi 470-1192, Japan \\ ${ }^{3}$ Department of Internal Medicine and Surgery, Fujita Health University School of Hygiene and Medicine, Toyoake, Aichi 470-1192, Japan \\ ${ }^{4}$ Ishizuki Thyroid Clinic, Naka-ku, Nagoya 460-0007, Japan \\ (Requests for offprints should be addressed to A Nagasaka, Department of Internal Medicine and Surgery, Fujita Health University School of Medicine, \\ Toyoake, Aichi 470-1192, Japan)
}

\begin{abstract}
Free radicals, hydroxyperoxides and $\mathrm{H}_{2} \mathrm{O}_{2}$ are all known to damage cell components. This study was designed to compare the concentrations of hydroxyperoxide and free radical scavengers in the cardiac muscles of old rats in the hyper- or hypothyroid condition, to determine whether rates of peroxidation would differ with age, thyroid status, or both.

Rats were rendered hyper- or hypothyroid by administration of L-thyroxine or methimazole for 4 weeks. Among the old rats, the lipid peroxide (LPO) concentrations, measured as thiobarbituric acid (TBA) reactants, were significantly greater in the hyperthyroid than in the euthyroid state and the LPO concentrations measured as $\mathrm{TBA}+\mathrm{Fe}^{3+}$ reactants, which may be precursors of LPO, were significantly greater in the hyperthyroid state, whereas in young rats, the LPO concentrations measured by TBA or TBA $+\mathrm{Fe}^{3+}$ methods did not differ significantly in the hyperthyroid state. In the euthyroid state, the concentration of $\mathrm{LPO}$ measured as $\mathrm{TBA}+\mathrm{Fe}^{3+}$ reactants was significantly reduced with age. Xanthine oxidase
\end{abstract}

(XOD) activity also was markedly increased with age, being more pronounced in the hyperthyroid than in the euthyroid state. The $\mathrm{Mn}$ and $\mathrm{Cu} / \mathrm{Zn}$ superoxide dismutase activities were greater in the hyperthyroid than in the euthyroid state. Glutathione peroxidase activity decreased with age in the euthyroid and, particularly, in the hyperthyroid state. Catalase activity was not affected in the old rats. Concentrations of $\alpha$-tocopherol in the old rats were high in the hyperthyroid state and low in the hypothyroid state, whereas the levels of $\beta$ - and $\gamma$-tocopherols in these rats were unchanged in both conditions as compared with the euthyroid state findings.

Data suggest that the site of free radical generation differs in older rats, with additional shifts in the location of intracellular lipid peroxidation being noted during hyperthyroidism. Thus, as rats age, the reduction of the free radical scavenger system and the increase in LPO and XOD activities might induce myocardial dysfunction.

Journal of Endocrinology (2000) 164, 97-102

\section{Introduction}

Lipid peroxidation in vivo is a fundamentally deteriorative reaction that is involved in aging processes (Barber \& Bernheim 1967, Muscari et al. 1990, Yoshikawa et al. 1990) and the development of atherosclerosis (Hartoroft 1965, Perkins et al. 1965). Lipid peroxidation occurs in polyunsaturated lipids and involves the direct reaction of oxygen and lipid to form free radical intermediates and semistable peroxides. These free radicals, hydroxyperoxides and $\mathrm{H}_{2} \mathrm{O}_{2}$, which damage the cell components (Tappel 1973) are putatively produced by the xanthine/ xanthine oxidase (XOD) reaction, the mitochondrial electron transport system, the peroxidation of arachidonic acids, and activated neutrophils.

The formation of lipid peroxides is increased in the hyperthyroid state (Asayama et al. 1987). Lipofuscin granules, which may be the products of lipid peroxidation (Marzabadi et al. 1992), are seen in cardiac muscle in the hypothyroid state (Koobs et al. 1978, Nakano \& Gotoh 1992). Lipid peroxidation may therefore influence the cardiac function of hyperthyroid and hypothyroid rats.

The free radical scavenger system consists of two famiies of enzymes, called the superoxide dismutases (SOD) (McCord et al. 1971). These enzymes catalyze the reaction $2 \mathrm{H}+2 \mathrm{O}_{2} \rightarrow \mathrm{H}_{2} \mathrm{O}_{2}+\mathrm{O}_{2}$ and help to minimize the cellular 
injury mediated by various free radicals (Gregory \& Fridovich 1973, Crapo \& McCord 1976). The two main types of SOD are $\mathrm{Mn}-\mathrm{SOD}$ and $\mathrm{Cu} / \mathrm{Zn}-\mathrm{SOD}$. In this study, we investigated the changes in lipid peroxide (LPO) concentration along with changes in superoxide and LPO metabolism in cardiac muscles obtained from hyper- and hypothyroid rats (Mano et al. 1995b). In addition, we measured the tissue concentrations of $\mathrm{Mn}-\mathrm{SOD}, \mathrm{Cu} / \mathrm{Zn}-$ SOD, XOD, glutathione peroxidase (GSH-PX) and catalase to determine whether they are modulated by lipid peroxidation.

\section{Materials and Methods}

\section{Animals}

Studies were conducted in two groups of male Wistar rats (Wistar-Imamichi Rat, obtained from Imamichi Institute for Animal Reproduction, Ibaraki, Japan), aged 8 weeks (young) and 1.5 years (old). They were fed a standard diet and distilled water throughout the experiment. The 30 old rats and 15 young rats were then treated as follows to induce hyper- or hypothyroidism. Subcutaneous injections of $200 \mu \mathrm{g}$ L-thyroxine $\left(\mathrm{L}-\mathrm{T}_{4}\right)$ were administered every other day for 30 days in six old rats and five young rats to induce hyperthyroidism, or $1 \mathrm{mg}$ methimazole (MMI) was administered daily for 30 days in six old rats and five young rats to induce hypothyroidism. The other 12 old rats were divided into two groups: six old rats were treated with $200 \mu \mathrm{g} \mathrm{L}-\mathrm{T}_{4}$ injection every day for 15 days and then $\mathrm{L}_{-} \mathrm{T}_{4}$-administration was withdrawn for 15 days (shortterm $\mathrm{L}-\mathrm{T}_{4}$-treated), and the other six old rats were treated with $200 \mu \mathrm{g}$ D-thyroxine $\left(\mathrm{D}-\mathrm{T}_{4}\right)$ injection every other day for 30 days. The $\mathrm{L}-\mathrm{T}_{4}$ and $\mathrm{D}-\mathrm{T}_{4}$ were dissolved in $0 \cdot 01 \mathrm{~N}$ $\mathrm{NaOH}$ and diluted with saline; the MMI was dissolved in saline. Control animals received injections of an equivalent volume of saline. On the 30th day after each treatment, the basal heart rate was measured before the administration of ether anesthesia. Blood samples for the determination of plasma concentrations of triiodothyronine $\left(\mathrm{T}_{3}\right)$ and $\mathrm{T}_{4}$ were obtained by cardiac puncture. The hearts were then removed, immediately frozen in liquid nitrogen, and stored at $-80{ }^{\circ} \mathrm{C}$ until required for assay.

\section{Samples of cardiac muscle}

Rat cardiac muscles were homogenized at $4{ }^{\circ} \mathrm{C}$ in $50 \mathrm{mM}$ Tris- $\mathrm{HCl}$ buffer, $\mathrm{pH} 7 \cdot 5$, to make a $10 \%(\mathrm{w} / \mathrm{v})$ homogenate, using a polytron homogenizer for $5 \mathrm{~min}$, followed by a sonic homogenizer for $3 \mathrm{~min}$. The homogenates were then centrifuged at $1000 \times \boldsymbol{g}$ for $15 \mathrm{~min}$ at $4{ }^{\circ} \mathrm{C}$. The resulting supernatants were collected and stored at $0{ }^{\circ} \mathrm{C}$ before use.
Measurement of LPO concentrations in rat cardiac muscle

Malondialdehyde (MDA), a secondary product of lipid peroxidation, was assayed by reacting the lipid peroxides with thiobarbituric acid (TBA) (Patton \& Kurtz 1951). MDA was assayed by the method reported by Ohkawa et al. (1979), and the products obtained when $1 \mathrm{mM} \mathrm{FeCl}_{3}$ was added before boiling were also measured.

Measurement of XOD activity in rat cardiac muscle

$\mathrm{XOD}$ was assayed as reported previously (Hashimoto 1974).

\section{Measurement of SOD activity in rat cardiac muscle}

Nitrite, which is a product of the oxidation of hydroxylammonium chloride by SOD, was measured under the following conditions. The incubation mixture $(0.8 \mathrm{ml})$ contained $0.5 \mathrm{ml}$ distilled water, $0.1 \mathrm{ml}$ boric acid buffer $(0.156 \mathrm{mM}), 0.1 \mathrm{ml}$ xanthine $(2 \mathrm{mM})$ and $0.1 \mathrm{ml}$ $\mathrm{NH}_{2} \mathrm{OH}(10 \mathrm{mM})$. The reaction was started by adding $20 \mathrm{U} / \mathrm{ml}$ XOD (Boehringer Mannheim, Mannheim, Germany) to the mixture, with heating in a water bath at $37^{\circ} \mathrm{C}$ for $30 \mathrm{~min}$. The nitrite concentration was determined as follows. After the addition to the reaction mixture of $2.0 \mathrm{ml} 3.6 \mathrm{mM} \quad \mathrm{N}-1$-naphthyl- $N^{\prime}$-diethylethylenediamine oxalate, $38 \mu \mathrm{M}$ sulfanilic acid and $2.0 \mathrm{ml}$ $100 \%$ acetic acid solutions, distilled water was added to obtain a final volume of $400 \mathrm{ml}$. After an incubation at $37^{\circ} \mathrm{C}$ for $45 \mathrm{~min}$, the absorbance of the reaction mixture was measured at $550 \mathrm{~nm}$ by spectrophotometer (Weisiger \& Fridovich 1973, Elstner \& Heupel 1976). To discriminate $\mathrm{Cu}, \mathrm{Zn}-\mathrm{SOD}$ and $\mathrm{Mn}-\mathrm{SOD}$, we used $1 \mathrm{mM}$ cyanide ion, which inactivates $\mathrm{Cu}, \mathrm{Zn}-\mathrm{SOD}$. SOD activities were proportional as a function of the enzyme volume.

\section{Measurement of catalase and GSH-PX activities in rat cardiac muscle}

Catalase and GSH-PX activities were assayed by a method reported previously (Hochstein \& Utley 1968, Aebi 1984).

\section{Measurement of cholesterol, triglyceride, co-enzyme $\mathrm{Q}$, and tochopherol concentrations in rat cardiac muscle}

Assays for cholesterol and triglyceride were performed as reported previously (Fletcher 1968, Zlatkis \& Zak 1969). Concentration of co-enzyme $\mathrm{Q}$ and of tocopherols were determined as reported previously (McCord et al. 1971).

\section{Measurement of serum concentrations of $T_{3}$ and $T_{4}$}

$\mathrm{T}_{3}$ and $\mathrm{T}_{4}$ concentrations in the sera of the hyper-, hypo- and euthyroid rats were measured with an 
Table 1 Thyroid status of the rats studied. Values are expressed as mean \pm S.E.M.

\begin{tabular}{|c|c|c|c|c|}
\hline & $\begin{array}{l}\mathbf{T}_{\mathbf{4}} \\
(\mu \mathrm{g} / \mathrm{l})\end{array}$ & $\begin{array}{l}\mathbf{T}_{3} \\
(\mu \mathrm{g} / \mathrm{l})\end{array}$ & $\begin{array}{l}\text { BW } \\
\text { (g) }\end{array}$ & $\begin{array}{l}\mathbf{H R} \\
\text { (beats/min) }\end{array}$ \\
\hline \multicolumn{5}{|l|}{ Group ( $n=6$ each group) } \\
\hline \multicolumn{5}{|l|}{ Rats aged 1.5 years } \\
\hline $\mathrm{L}^{-\mathrm{T}_{4} \text {-treated (hyperthyroid) }}$ & $152 \cdot 0 \pm 8 \cdot 4^{*}$ & $4 \cdot 46 \pm 2 \cdot 27^{*}$ & $380 \pm 11^{*}$ & $342 \pm 14^{*}$ \\
\hline MMI-treated (hypothyroid) & $26 \cdot 2 \pm 3 \cdot 0^{*}$ & $0.45 \pm 0.04^{*}$ & $435 \pm 6$ & $235 \pm 18$ \\
\hline Short-term $\mathrm{L}_{-} \mathrm{T}_{4}$-treated & $39 \cdot 5 \pm 2 \cdot 4$ & $0.63 \pm 0.03$ & $399 \pm 8$ & $274 \pm 19$ \\
\hline \multicolumn{5}{|l|}{ Rats aged 8 weeks } \\
\hline Saline-treated (euthyroid) & $40 \cdot 2 \pm 2 \cdot 3$ & $0.65 \pm 0.08$ & $348 \pm 9$ & $272 \pm 20$ \\
\hline $\mathrm{L}-\mathrm{T}_{4}$-treated (hyperthyroid) & $182 \cdot 1 \pm 15 \cdot 1^{*}$ & $3 \cdot 42 \pm 0 \cdot 40^{*}$ & $310 \pm 6^{*}$ & $340 \pm 15^{*}$ \\
\hline MMI-treated (hypothyroid) & $28 \cdot 0 \pm 4 \cdot 9^{*}$ & $0 \cdot 48 \pm 0 \cdot 19$ & $339 \pm 17$ & $240 \pm 17$ \\
\hline
\end{tabular}

BW, body weight; $\mathrm{HR}$, heart rate. ${ }^{*} P<0 \cdot 05$ compared with saline-treated rats.

immunochemiluminescence kit according to the manufacturer's instructions (Amersham Co. Ltd, Amersham, Bucks, UK).

\section{Protein assays}

Protein concentration in cardiac muscle was determined with a Bio-Rad protein assay kit, with bovine serum albumin used as a standard (Bradford 1976).

\section{Statistical analyses}

Data are expressed as mean \pm s.E.M Differences between data sets were evaluated by analysis of variance (ANOVA) post hoc test or Welch's test.

The intra-assay and interassay coefficients of variation for these assays were within $7 \cdot 5 \%$. A level of $P<0 \cdot 05$ was accepted as statistically significant.

\section{Results}

The thyroid status of the rats was confirmed by measuring serum concentrations of $\mathrm{T}_{4}$ and $\mathrm{T}_{3}$. The concentrations of these hormones were significantly increased in the hyperthyroid rats and low in the hypothyroid rats, compared with the concentrations in the euthyroid rats. In the young hypothyroid rats, the serum concentrations of $\mathrm{T}_{3}$ were also low, but not to a statistically significant extent (Table 1).

The body weights and heart rates were determined in each age group during the experiment. The weight of the whole heart was also measured at the time of decapitation. The body weight of the hyperthyroid rats was significantly less than that of either the hypo- or euthyroid rats $(P<0 \cdot 05)$. The short-term $\mathrm{L}_{-} \mathrm{T}_{4}$-treated or $\mathrm{D}-\mathrm{T}_{4}$-treated rats did not show any changes in these hormones, body weight and heart rate (Table 1). Body weight did not differ significantly between the hypothyroid and euthyroid rats, regardless of age. Organ weights were not significantly affected by thyroid status, except for the heart, which was significantly heavier in the rats treated with L-thyroxine than in the saline-treated (euthyroid) young rats (data not shown).

In both age groups, the heart rate of the hyperthyroid animals significantly exceeded that of the euthyroid animals. Conversely, the heart rate of the hypothyroid animals did not differ significantly from that of the euthyroid animals in either age group.

Under the experimental conditions, the serum concentrations of thyroid hormone did not affect the protein : wet weight ratio of organ tissue (data not shown).

\section{LPO concentrations}

The concentrations of LPO, estimated as TBA reactants, were greater in the old hyperthyroid rats than in all the other groups. However, the concentrations of LPO, estimated as $\mathrm{Fe}$-added TBA $\left(\mathrm{TBA}+\mathrm{Fe}^{3+}\right)$ reactants, were increased in the old $\mathrm{T}_{4}$-treated rats compared with those in the age-matched saline-treated rats. These concentrations were not changed in the short-term $\mathrm{L}-\mathrm{T}_{4}$-treated or $\mathrm{D}-\mathrm{T}_{4}$-treated rats. They were lower in the saline-treated and MMI-treated aged rats compared with the correspondingly treated young rats (Table 2).

\section{XOD concentrations}

The concentration of XOD was low, but detectable, in rat cardiac muscle. The concentration in the old hyperthyroid rats exceeded that in the age-matched euthyroid rats, and the concentrations in the short-term $\mathrm{L}-\mathrm{T}_{4}$-treated or $\mathrm{D}-\mathrm{T}_{4}$-treated rats were not different from that of the saline-treated rats. The concentration of XOD in the old rats significantly exceeded that in the young rats across all conditions of thyroid activity (Table 3 ). 
Table 2 LPO concentrations in cardiac muscle from old ( 1.5 years) and young ( 8 weeks) rats. Values are mean \pm S.E.M. of six animals studied

\begin{tabular}{|c|c|c|c|c|}
\hline & \multicolumn{4}{|c|}{ Lipid peroxide (nmol/mg protein) } \\
\hline & \multicolumn{2}{|l|}{ TBA } & \multicolumn{2}{|l|}{$\mathrm{TBA} \pm \mathrm{Fe}^{3+}$} \\
\hline & Old & Young & Old & Young \\
\hline \multicolumn{5}{|l|}{ Group } \\
\hline Saline-treated & $0.623 \pm 0.03$ & $0 \cdot 88 \pm 0 \cdot 15$ & $7 \cdot 03 \pm 1 \cdot 00 \dagger$ & $12 \cdot 45 \pm 1 \cdot 42$ \\
\hline $\mathrm{L}-\mathrm{T}_{4}$-treated & $0 \cdot 857 \pm 0 \cdot 08^{*}$ & $1 \cdot 19 \pm 0 \cdot 26$ & $12 \cdot 23 \pm 0 \cdot 90^{*}$ & $11 \cdot 29 \pm 0 \cdot 35$ \\
\hline MMI-treated & $0 \cdot 626 \pm 0 \cdot 07$ & $0 \cdot 87 \pm 0 \cdot 11$ & $8 \cdot 41 \pm 0 \cdot 22 \dagger$ & $12 \cdot 18 \pm 1 \cdot 65$ \\
\hline Short-term L-T -treated & $0 \cdot 77 \pm 0 \cdot 09$ & & $8 \cdot 20 \pm 1 \cdot 08$ & \\
\hline $\mathrm{D}-\mathrm{T}_{4}$-treated & $0.63 \pm 0.08$ & & $8 \cdot 45 \pm 0 \cdot 76$ & \\
\hline
\end{tabular}

TBA, measured as thiobarbituric acid reactants; $\mathrm{TBA}+\mathrm{Fe}^{3+}$, measured as thiobarbituric acid reactants when the reaction mixture contains $\mathrm{Fe}^{3+}$.

$P<0.05$ compared with ${ }^{*}$ saline-treated rats or +8 -week-old rats.

\section{SOD concentrations}

The total SOD concentrations were not changed in the old rats, but were significantly increased after $\mathrm{L}-\mathrm{T}_{4}$ treatment in the young hyperthyroid rats. The Mn-SOD concentrations were significantly increased only in the old hyperthyroid rats relative to the remaining groups. The $\mathrm{Cu} / \mathrm{Zn}$-SOD levels were not changed in the old or the young rats. None of these concentrations was affected by the short-term $\mathrm{L}-\mathrm{T}_{4}$ treatment or $\mathrm{D}-\mathrm{T}_{4}$ treatment (Table 4).

\section{GSH-PX and catalase concentrations}

GSH-PX concentration showed a reduction with age, with a significant difference in values between the old euthyroid and hyperthyroid rats.

GSH-PX and catalase concentrations were not different between the saline-treated rats and the short-term $\mathrm{L}-\mathrm{T}_{4}$-treated or $\mathrm{D}-\mathrm{T}_{4}$-treated rats (Table 5).

Total cholesterol, triglyceride, co-enzyme Q, and tocopherol concentrations

No differences in the concentrations of total cholesterol, triglyceride, or co-enzyme $\mathrm{Q}$ were obtained between any of the rat groups (data not shown).

Table 3 XOD activity in cardiac muscle from old ( 1.5 years) and young ( 8 weeks) rats. Values are mean \pm S.E.M. of six animals studied

Activity (mIU/mg protein)

\section{Group}

$\begin{array}{lll}\text { Saline-treated } & 0 \cdot 17 \pm 0 \cdot 02 \dagger & 0 \cdot 11 \pm 0 \cdot 06 \\ \text { L-T }_{4} \text {-treated } & 0 \cdot 22 \pm 0 \cdot 04^{*} \dagger & 0 \cdot 12 \pm 0 \cdot 06 \\ \text { MMl-treated } & 0 \cdot 19 \pm 0 \cdot 02 \dagger & 0 \cdot 09 \pm 0 \cdot 03 \\ \text { Short-term L-T } & \\ \text { D-T }-T_{4} \text {-treated } & 0 \cdot 27 \pm 0 \cdot 10 & \\ & 0 \cdot 20 \pm 0.09 & \\ \end{array}$

$P<0 \cdot 05$ compared with *saline-treated rats or $\uparrow 8$-week-old rats.
The concentration of $\alpha$-tocopherol was significantly increased in the old hyperthyroid rats, and was significantly decreased in the old hypothyroid rats, compared with the values obtained in euthyroid rats of that age (Table 6).

\section{Discussion}

Among the hyperthyroid animals, in the old rats Mn-SOD concentration was increased relative to either euthyroid or hypothyroid conditions, whereas in the young rats, total SOD concentrations were increased. These results corroborate the findings of Asayama et al. (1987), who demonstrated that Mn-SOD concentrations increased 4 weeks after $\mathrm{T}_{4}$ administration.

The formation of superoxide activated by thyroid hormone may occur mainly in the mitochondrial respiratory system. However, the xanthine/XOD reactions, the arachidonic acid cascade, or both, may be involved in this process. An immunocytochemical study showed that $\mathrm{Mn}-\mathrm{SOD}$ was present in mitochondria, and that $\mathrm{Cu} / \mathrm{Zn}$ SOD was localized in the cytoplasm (Slot et al. 1985). Thus, in hyperthyroidism, Mn-SOD may be induced to protect the mitochondria from oxidative injury by superoxide.

Among the old rats analyzed in our present study, the concentrations of XOD were increased in each thyroid state, with the hyperthyroid animals having the largest increase compared with that in the young rats. The old rats also exhibited lower concentrations of LPO than the young rats, but these were increased in the hyperthyroid state. The generation of LPO in the old rats may occur mainly via XOD activation, particularly in the activated mitochondrial respiration observed during the hyperthyroid state.

The LPO concentration measured by TBA was increased only in the old hyperthyroid rats. The LPO concentrations measured as $\mathrm{TBA}+\mathrm{Fe}^{3+}$ may be the precursors of the concentrations measured as TBA reactants 
Table 4 SOD acitivity in cardiac muscle from old ( 1.5 years) and young ( 8 weeks) rats, expressed as $\mu$ g/mg protein, using purified bovine erythrocyte SOD (Sigma Chemical Co., St Louis, MO, USA) as the standard enzyme protein. Values are mean \pm S.E.M. of six animals studied

\begin{tabular}{|c|c|c|c|c|c|c|}
\hline & \multicolumn{2}{|c|}{ Total SOD ( $\mu \mathrm{g} / \mathrm{mg}$ protein) } & \multicolumn{2}{|c|}{ Mn-SOD ( $\mu \mathrm{g} / \mathrm{mg}$ protein) } & \multicolumn{2}{|c|}{$\mathbf{C u}, \mathbf{Z n}-\mathbf{S O D}(\mu \mathrm{g} / \mathrm{mg}$ protein $)$} \\
\hline \multicolumn{7}{|l|}{ Group } \\
\hline $\mathrm{L}^{-\mathrm{T}_{4}}$-treated & $2 \cdot 10 \pm 0 \cdot 20$ & $3 \cdot 35 \pm 0.69^{*}$ & $0 \cdot 98 \pm 0 \cdot 13^{*}$ & $0 \cdot 83 \pm 0 \cdot 31$ & $1 \cdot 84 \pm 0 \cdot 27$ & $2 \cdot 03 \pm 0 \cdot 58$ \\
\hline MMI-treated & $2 \cdot 22 \pm 0 \cdot 16$ & $2 \cdot 53 \pm 0 \cdot 46$ & $0.60 \pm 0.07$ & $0 \cdot 75 \pm 0 \cdot 24$ & $1 \cdot 84 \pm 0 \cdot 18$ & $1 \cdot 78 \pm 0 \cdot 35$ \\
\hline Short-term L-T -treated & $2 \cdot 27 \pm 0 \cdot 25$ & & $0.68 \pm 0.07$ & & $1 \cdot 86 \pm 0 \cdot 19$ & \\
\hline
\end{tabular}

${ }^{*} P<0.05$ compared with saline-treated rats.

(Wills 1964, Demopulos 1973). The LPO concentration estimated as $\mathrm{TBA}+\mathrm{Fe}^{3+}$ reactants in the old hyperthyroid rats exceeded that in the old euthyroid rats, suggesting that the production of LPO in the cardiac muscle of the older hyperthyroid rats exceeded its turnover. In the old hypoand euthyroid rats, the concentration of LPO measured as $\mathrm{TBA}+\mathrm{Fe}^{3+}$ reactants was decreased, suggesting that the formation and turnover of LPO were both diminished. This may lead to the production of lipofuscin granules, which are found only in the myocardium of hypothyroid animals.

Salminen et al. (1988) reported that the unstimulated peroxidation rate decreases with age. Lemeshko et al.
(1981) showed that an age-related decrease in the rate of lipid peroxidation in the rat liver was due to a decrease in enzymatic lipid peroxidation in the microsomes, and to an increase in the concentrations of NADPH-dependent antioxidants in the cytoplasm of liver cells. Barrett \& Horton (1975) observed an increase in total peroxidation capacity in muscle mitochondria and microsomes between the age of 1 and 8 months. Therefore, the difference in the LPO concentrations observed between the old and young rats in our study may be due to the site of LPO generation. Combining these LPO data with our GSH-PX findings, it appears that lipid peroxidation was affected by aging, as shown in our previous study of the aged rat brain (Mano

Table 5 GSH-PX and catalase activity in cardiac muscle from old ( 1.5 years) and young ( 8 weeks) rats. Values are mean \pm S.E.M. of six animals studied

\begin{tabular}{|c|c|c|c|c|}
\hline & \multicolumn{2}{|c|}{ GSH-PX (mIU/mg protein) } & \multicolumn{2}{|c|}{ Catalase (IU/mg protein) } \\
\hline & Old & Young & Old & Young \\
\hline \multicolumn{5}{|l|}{ Group } \\
\hline Saline-treated & $169 \pm 11 \dagger$ & $237 \pm 15$ & $17 \cdot 68 \pm 2 \cdot 49$ & $15 \cdot 71 \pm 2 \cdot 33$ \\
\hline $\mathrm{L}^{-\mathrm{T}_{4}}$-treated & $87 \pm 27^{*} \dagger$ & $207 \pm 18$ & $18 \cdot 25 \pm 1 \cdot 84$ & $18 \cdot 25 \pm 1 \cdot 97$ \\
\hline MMI-treated & $172 \pm 20 \dagger$ & $256 \pm 19$ & $18 \cdot 45 \pm 2 \cdot 04$ & $14 \cdot 22 \pm 2 \cdot 96$ \\
\hline Short-term L-T -treated & $179 \pm 16$ & & $18 \cdot 32 \pm 2 \cdot 51$ & \\
\hline $\mathrm{D}-\mathrm{T}_{4}$-treated & $168 \pm 23$ & & $17 \cdot 15 \pm 2 \cdot 22$ & \\
\hline
\end{tabular}

$P<0.05$ compared with *saline-treated rats or $\nmid 8$-week-old rats.

Table 6 Tocopherol (Toc.) concentrations in cardiac muscle from old rats (data in parentheses are those of young ( 8 week-old) rats. Values are mean \pm S.E.M. of six animals studied

Tocopherols $(\mu \mathrm{g} / \mathrm{l}$ homogenate)

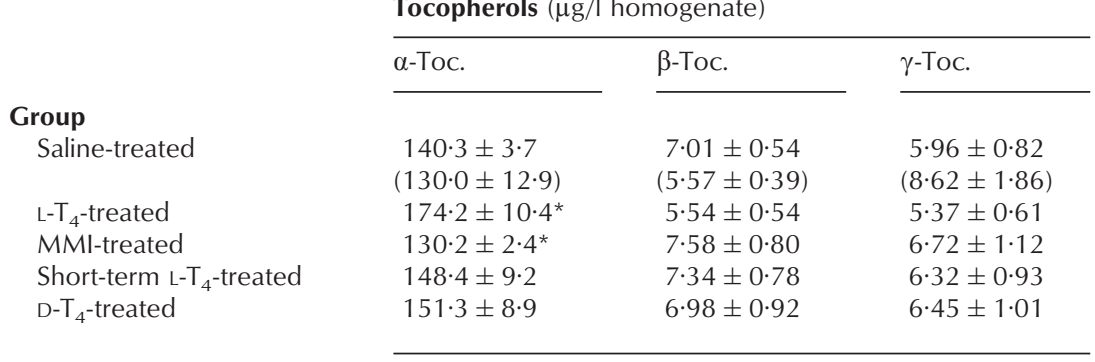

${ }^{*} P<0 \cdot 05$ compared with saline-treated rats. 
et al. 1995a). Such alterations in lipid peroxidation may cause cardiac dysfunction in an older hyperthyroid animal.

Though there were no differences in total cholesterol, triglyceride, or co-enzyme Q concentrations, the concentrations of $\alpha$-tocopherol were slightly increased in the old hyperthyroid and hypothyroid rats, which suggests that this substance may act as a free radical scavenger.

These events in rats in an $\mathrm{L}_{-} \mathrm{T}_{4}$-induced hyperthyroid state were reversed by withdrawing the short-term administered $\mathrm{L}-\mathrm{T}_{4}$. The $\mathrm{D}-\mathrm{T}_{4}$ treatment did not affect these indicators. These data imply that these changes may be specific for $\mathrm{L}_{-} \mathrm{T}_{4}$-induced hyperthyroidism, but not for $\mathrm{D}-\mathrm{T}_{4}$ treatment, which does not induce the hyperthyroid state.

\section{Acknowledgements}

The authors thank Ms N Takekawa for her secretarial assistance.

This work was supported by a grant from the Ishizuki Thyroid Science Foundation, Nagoya, Japan.

\section{References}

Aebi H 1984 Catalase in vitro. Methods in Enzymology 105 121-126. Asayama K, Dobashi K, Hayashibe H, Megata Y \& Kato K 1987 Lipid peroxidation and free radical scavengers in thyroid dysfunction in the rat: a possible mechanism of injury to heart and skeletal muscle in hyperthyroidism. Endocrinology 121 2112-2118.

Barber AA \& Bernheim F 1967 Lipid peroxidation: its measurement, occurrence, and significance in animal tissues. In Advances in Gerontological Research, vol 2, pp 355-403. Ed BL Strehler. New York: Academic Press.

Barrett MC \& Horton AA 1975 Age-related changes in lipid peroxidation in rat liver mitochondria. Biochemical Society Transactions $\mathbf{3}$ 124-126.

Bradford M 1976 A rapid and sensitive method for quantitation of microgram quantities of protein utilizing the principle of proteindye binding. Analytical Biochemistry 72 248-254.

Crapo JP \& McCord JM 1976 Oxygen induced changes in pulmonary superoxide assayed by antibody titrations. American Journal of Physiology 231 1196-1203.

Demopulos HB 1973 Control of free radicals in biologic systems. Federation Proceedings 32 1903-1908.

Elstner EF \& Heupel 1976 Inhibition of nitrite formation from hydroxylammoniumchloride: a simple assay for superoxide dismutase. Analytical Biochemistry 70 616-620.

Fletcher MJ 1968 A colorimetric method for estimating serum triglycerides. Clinica et Chimica Acta 22 393-397.

Gregory EM \& Fridovich I 1973 The induction of superoxide dismutase by molecular oxygen. Journal of Bacteriology 114 543-548.

Hartoroft WS 1965 Atheroma begins at birth. In Metabolism of Lipids as Related to Atherosclerosis, pp 18-25. Ed FA Kummerow. Springfield, IL, USA: Charles C Thomas.

Hashimoto S 1974 A new spectrophotometric assay method of xanthine oxidase in crude tissue homogenate. Analytical Biochemistry $62426-435$.
Hochstein P \& Utley H 1968 Hydrogen peroxide detoxication by glutathione peroxidase and catalase in rat liver homogenate. Molecular Pharmacology 4 574-579.

Koobs DH, Schultz RL \& Jutzy RV 1978 The origin of lipofuscin and possible consequences to the myocardium. Archives of Pathology and Laboratory Medicine 102 66-68.

Lemeshko VV, Kaliman PA \& Nikitchenko YV 1981 Lipid peroxidation in the postnuclear and microsomal fractions of rat liver homogenates upon ageing. Biokhimiia 46 620-627.

McCord JM, Keele Jr BB \& Fridovich I 1971 An enzyme-based theory of obligate anaerobiosis: the physiological function of superoxide dismutase. Proceedings of the National Academy of Sciences of the USA 68 1024-1027.

Mano T, Shinohara R, Sawai Y, Oda N, Nishida Y, Mokuno T, Asako K, Ito Y, Kotake M, Hamada M, Nakai A \& Nagasaka A $1995 a$ Changes in lipid peroxidation and free radical scavengers in the brain of hyper- and hypothyroid aged rats. Journal of Endocrinology 147 361-365.

Mano T, Shinohara R, Sawai Y, Oda N, Nishida Y, Mokuno T, Kotake M, Hamada M, Masunaga R, Nakai A \& Nagasaka A $1995 b$ Effects of thyroid hormone on coenzyme Q and other free radical scavengers in rat heart muscle. Journal of Endocronology 145 131-136.

Marzabadi MR, Yin D \& Brunk UT 1992 Lipofuscinogenesis in a model system of cultured cardiac myocytes. EXS 62 78-88.

Muscari C, Caldarera CM \& Guarnieri C 1990 Age-dependent production of mitochondrial hydrogen peroxide, lipid peroxides and fluorescent pigments in the rat heart. Basic Research in Cardiology 85 $172-178$.

Nakano M \& Gotoh S 1992 Accumulation of cardiac lipofuscin depends on metabolic rate of mammals. Journal of Gerentology 47 B126-B129.

Ohkawa H, Ohnishi N \& Yagi K 1979 Assay for lipids peroxides in animal tissues by thiobarbituric acid reaction. Analytical Biochemistry 95 351-358.

Patton S \& Kurtz GW 1951 2-Thiobarbituric acid as a reagent for detecting milk fat oxidation. Journal of Dairy Sciences 34 669-674.

Perkins EG, Joh TH \& Kummerow FA 1965 The composition of the extractable and bound lipids of the human aorta. In Metabolism of Lipids as Related to Atherosclerosis, pp 48-61. Ed FA Kummerow. Springfield, IL, USA: Charles C Thomas.

Salminen A, Saari P \& Kihlstrom M 1988 Age- and sex-related differences in lipid peroxidation of mouse cardiac and skeletal muscles. Comparative Biochemistry and Physiology 89B 695-699.

Slot JW, Genze HJ, Freeman BA \& Crapo JD 1985 Intracellular localization of the copper-zinc and manganese superoxide dismutases in rat liver parenchymal cells. Laboratory Investigation $\mathbf{5 5}$ 363-371.

Tappel AL 1973 Lipid peroxidation damage to cell components. Federation Proceedings 32 1870-1874.

Weisiger RA \& Fridovich I 1973 Superoxide dismutase. Journal of Biological Chemistry 248 3582-3592.

Wills ED 1964 The effect of inorganic iron on the thiobarbituric acid method for the determination of lipid peroxides. Biochimica et Biophysica Acta 84 475-477.

Yoshikawa T, Naito Y \& Kondo M 1990 Free radical involvement in the aging process. Neuroscience 16 603-612.

Zlatkis A \& Zak B 1969 Study of a new cholesterol reagent. Analytical Biochemistry 29 143-148.

Received 18 May 1999

Accepted 31 August 1999 